\title{
Phaeochromocytoma in a coeliac ganglion in pregnancy
}

\author{
J. PARSONS \\ M.R.C.O.G.
}

\author{
R. W. D. Clunie \\ M.B., Ch.B., D.A., F.F.A.R.C.S.
}

\author{
A. T. LETCHWORTH \\ M.D., F.R.C.O.G. \\ Royal Hampshire County Hospital, Winchester, Hants 5022 5DG
}

\begin{abstract}
Summary
A case of a phaeochromocytoma is reported which presented as collapse in the postpartum period. The site of the tumour was in the coeliac ganglion.
\end{abstract}

KEY WORDS: pulmonary oedema, supraventricular tachycardia, hypotensive shock, eclampsia.

\section{Introduction}

Phaeochromocytoma is a rare tumour which is associated, in pregnancy, with a maternal mortality of $48 \%$ (Schenker and Chowers, 1971). It is usually associated with paroxysmal or sustained hypertension with or without proteinuria, but it can be a cause of unexplained collapse in an obstetric patient (Fox et al., 1969). The supra-renal gland is the site of the tumour in $98 \%$ of cases, and the remaining $2 \%$ arise in the coeliac ganglion (Blair, 1963). Our case is reported because there was a transient rise of blood pressure only, and the tumour was in the coeliac ganglion.

\section{Case report}

The patient was a 19-year-old multigravida. Her first pregnancy had been terminated at 20 weeks gestation, with the aid of prostaglandins. Her second pregnancy, at another hospital, was complicated by an eclamptic fit during labour. The baby died shortly after delivery from hypoxia. The patient had a transient paralysis of her left arm, but subsequently made an uneventful recovery.

She presented antenatally at the Royal Hampshire County Hospital, in her third pregnancy at 23 weeks gestation, with a booking blood pressure of 130/80 $\mathrm{mmHg}$. Her antenatal care was uneventful, and she remained normotensive at each of her 16 visits. She was admitted in strong labour at 38 weeks gestation. The blood pressure was $120 / 80 \mathrm{mmHg}$ on admission, and $2 \mathrm{hr}$ later a live male infant, weight $2600 \mathrm{~g}$, was delivered. A blood pressure of $170 / 120 \mathrm{mmHg}$ was noted on one occasion during the second stage of labour which lasted $24 \mathrm{~min}$. The blood pressure following delivery was $130 / 100 \mathrm{mmHg}$ and diazepam $5 \mathrm{mg}$ was given intramuscularly. The episiotomy was sutured, and the blood pressure remained stable. Two hours after delivery she collapsed, and although conscious was confused.

Examination revealed a weak thready pulse of 120-130 per min, unrecordable blood pressure and respiratory rate of 40 per min. She became cyanosed with clinical and biochemical evidence of respiratory failure. Pulmonary oedema with bilateral early consolidation in both lungs was seen on the chest X-ray. A presumptive diagnosis of amniotic fluid embolism was made. Intubation, and ventilation with $100 \%$ oxygen was instituted, and sodium bicarbonate, methyl prednisolone, frusemide and ampicillin were given intravenously. The electrocardiograph showed a supraventicular tachycardia which did not respond to verapamil or digoxin, or to synchronised direct current conversion. Death occurred $6 \mathrm{hr}$ after delivery.

At post-mortem, the larynx and air passages were congested and all lobes of the lungs were grossly oedematous, with areas of recent haemorrhagic collapse. An irregularly lobulated tumour without haemorrhage or infarction, 4 inches in diameter, was present on the posterior abdominal wall on the left side, 2 inches below the kidney. Histologically this was a paraganglioma of the aortico-sympathetic region. The tumour was assessed by Dr Polak at the Royal Postgraduate Medical School, by immunochemical techniques, and tumour cells were completely unreactive to any of the 31 antibodies used. The cause of death was acute pulmonary oedema.

\section{Discussion}

The dominant presenting feature of this case was postpartum collapse with acute respiratory failure, and supraventricular tachycardia. The absence of 
sustained hypertension is a recognised, though rare, presentation of phaeochromocytoma.

The absence of active pressor substances was probably the result of inappropriate fixation of the tumour. In retrospect the hypertension and convulsions during her second pregnancy were probably also due to this phaeochromocytoma. Since $10 \%$ of pregnant patients with this tumour have convulsions (Schenker and Chowers, 1971) it would seem wise to check all patients with a history of eclamptic fits for raised levels of plasma catecholamines.

We report this case to emphasise the fact that phaechromocytoma may have a similar presentation to other life-threatening obstetric crises, and should be considered in the differential diagnosis.

\section{Acknowledgments}

We would like to thank $\operatorname{Dr} A$. Vicenti for the pathology report, $D \bar{Z}$ Polak for immunochemical analysis, Dr K. Packer for help with the manuscript, and Miss $\mathbf{J}$. Lee for secretarial assistance.

\section{References}

BLAIR, R.G. (1963) Pheochromocytoma and pregnancy. Journal of Obstetrics and Gynaecology of the British Empire, 70, 110.

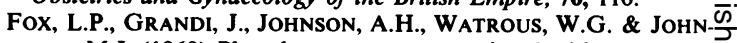
SON, M.J. (1969) Pheochromocytoma associated with pregnancy American Journal of Obstetrics and Gynecology, 104, 288.

SCHENKER, J.G. \& CHOWERS, J. (1971) Pheochromocytoma andês pregnancy. Obstetrical and Gynecological Survey, 26, 739.

(Accepted 26 January 1984) 